\title{
Scrap, carbon and cost savings from the adoption of flexible nested blanking
}

\author{
Iain P. Flint ${ }^{1}$. Julian M. Allwood ${ }^{1}$. André Cabrera Serrenho ${ }^{1}$ (1) \\ Received: 30 November 2018 / Accepted: 10 June 2019 / Published online: 21 June 2019 \\ (C) The Author(s) 2019
}

\begin{abstract}
Steel accounts for $6 \%$ of anthropogenic $\mathrm{CO}_{2}$ emissions, most of which arises during steelmaking rather than downstream manufacturing. While improving efficiency in steelmaking has received a great deal of attention, improving material yield downstream can have a substantial impact and has received comparatively less attention. In this paper, we explore the conditions required for manufacturers to switch to a more materially efficient process, reducing demand for steel and thus reducing emissions without reducing the supply of goods to consumers. Furthermore, we present an alternative processing route where parts can be cut in flexible arrangements to take advantage of optimal nesting across multiple part geometries. For the first time, we determine the potential savings that flexible nested blanking of parts could achieve by calculating the potential for grouping orders with tolerably similar thickness, strengths, ductility and corrosion-resistance. We found that $1080 \mathrm{kt}$ of $\mathrm{CO}_{2}$ and $710 \mathrm{kt}$ of steel worth $€ 430 \mathrm{M}$ could be saved each year if this scheme was adopted across all European flat steelmills serving the automotive sector.
\end{abstract}

Keywords Sheet metal forming $\cdot$ Blanking $\cdot$ Laser cutting $\cdot$ Scrap reduction $\cdot \mathrm{CO}_{2}$

\section{Introduction}

$1628 \mathrm{Mt}$ of crude steel was produced in 2016 [23] with an associated emission of $3.1 \mathrm{Gt} \mathrm{CO}_{2}$ to the atmosphere, giving it the highest climate change impact of any material and accounting for $6 \%$ of global emissions [3]. While improvements in energy efficiency have halved emissions per tonne over the past 50 years [22] and the share of scrapbased electric arc furnace production has increased from $12 \%$ in 1960 to $25 \%$ in 2015 [24], demand for steel has more than quadrupled, meaning that total emissions have more than doubled over the same period. Clearly more must be done, and this is possible through material efficiency: using less material to achieve the same level of service.

This study focuses on flat steel-sheets produced by rolling thick slabs into long, thin coils-as opposed to long products-beams and bars rolled from billets and extruded products such as rebar and wire. The majority of flat

André Cabrera Serrenho

ag806@cam.ac.uk

1 Department of Engineering, University of Cambridge, Trumpington Street, Cambridge CB2 1PZ, UK steel process scrap arises during manufacturing and each tonne avoided saves around 1.3 tonnes of $\mathrm{CO}_{2}$. Specifically, we focus on the automotive industry where yield losses are the highest of any sector. Excluding the mining and beneficiation of ore and coal, the production process of goods from flat steel can be broken down into two key stages: steelmaking and manufacturing. Figure 1 shows these stages as a Sankey diagram for the production of vehicles from galvanised steel, which accounted for more than $60 \%$ of European automotive flat steel demand in 2016 [9]. Table 1 shows the process yield and emissions for each stage in Fig. 1.

The majority of emissions arise during the steelmaking phase, primarily from oxidation of coke used to heat and reduce iron ore as well as decarburisation of the hot metal, emitting $1.47 \mathrm{t} \mathrm{CO}_{2} / \mathrm{t}$ liquid steel produced [17]. Casting, rolling and finishing contribute a further $0.48 \mathrm{t} \mathrm{CO}_{2} / \mathrm{t}$ of finished steel, but because of yield losses the intensity of galvanised steel climbs to $2.35 \mathrm{t} \mathrm{CO}_{2} / \mathrm{t}$. Milford et al. [20] estimate manufacturing emissions for blanking and stamping much lower at 0.02 and $0.07 \mathrm{t} \mathrm{CO}_{2} / \mathrm{t}$ output respectively, though because of substantial yield losses at these processes as observed by Horton and Allwood [15] embodied emissions rise to $4.06 \mathrm{t} \mathrm{CO}_{2} / \mathrm{t}$ of steel in the final product. This value is higher than the value calculated by 


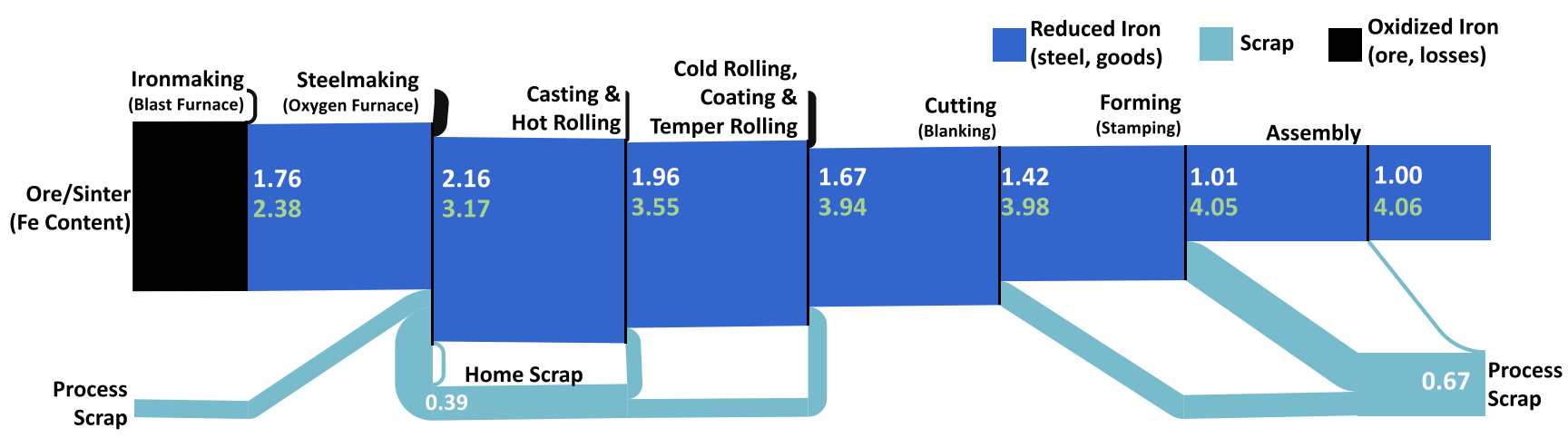

Fig. 1 Sankey diagram showing the flows through steelmaking and manufacturing processes required to produce one tonne of steel in an automotive product. The first four processes occur in the steel mill while the final three processes occur downstream at manufacturing

Milford et al. due to greater yield losses in steelmaking based upon the most recent data from worldsteel.

Improving yield at any process reduces emissions; however, the further downstream action is taken the greater the effect will be. A $1 \%$ point improvement in steelmaking yield would reduce carbon emissions by $0.8 \%$, while the same improvement at the stamping stage would lead to a $1.4 \%$ reduction. Yield improvements in the steelmaking process are also harder to come by than those further downstream. While over a quarter of the iron input to the steelmaking stage is lost as oxide or scrap, the steel industry has been working effectively for decades to minimise these losses due to the substantial economic incentives to do so. While technology such as thin-strip casting [7] and the Hisarna process [1] are promising, worldsteel estimate that further improvements are likely to be only marginal and primarily a result of better process management. Meanwhile, similar losses occur downstream during manufacturing where over a third of material input ends up as scrap and greater intervention is possible.

Table 1 Process yields and emissions per tonne of output for each of the processes shown in Fig. 1

\begin{tabular}{lcc}
\hline Process & $\begin{array}{c}\text { Yield } \\
\%\end{array}$ & $\begin{array}{c}\text { Process emissions } \\
\mathrm{t} \mathrm{CO}_{2} / \mathrm{t} \text { output }\end{array}$ \\
\hline Ironmaking & $98.3^{1}$ & $1.35^{2}$ \\
Steelmaking & $91.9^{1}$ & $0.12^{2}$ \\
Casting and hot rolling & $90.7^{1}$ & $0.19^{3}$ \\
Pickling, rolling and coating & $85.5^{1}$ & $0.23^{3}$ \\
Cutting & $85.0^{4}$ & $0.03^{3}$ \\
Forming & $71.0^{4}$ & $0.07^{3}$ \\
Assembly & $99.0^{4}$ & $0.01^{4}$ \\
\hline
\end{tabular}

Sources: ${ }^{1}$ World Steel Association Process Yield Survey, ${ }^{2}$ IPCC [17] ${ }^{3}$ Milford et al. [20], ${ }^{4}$ Horton and Allwood [15] and site tours sites. Numbers in white are mass flows while numbers in green are $\mathrm{CO}_{2}$ emissions. Note that scrap is assigned no embodied emissions in this analysis. All numbers in tonnes

One third of the losses in automotive manufacturing arise from cutting flat parts from the coil using a blanking press, while most of the remaining yield losses arise during stamping of parts, with a small loss during the following finishing and assembly processes due to quality control. Cutting losses occur as the desired blank is not always rectangular, while stamping losses arise from the need to provide material around the part for the stamping press to grip, as well as addendum material that is formed with the desired part to prevent wrinkling or tearing, but later removed.

The stamping process design is unique for each part; however, every blank is essentially cut from the coil the same way. Although there are opportunities to improve existing stamping processes, most savings can be obtained by using less metal [14]. In theory, multiple geometries could be cut from the same coil of material using a more complex blanking die, as is the practice in the garment, shoe and wooden furniture industries [5, 18]. Optimised nesting during blanking has achieved process yields of up to $95 \%$ for multiple irregular parts with yields increasing as more components are available to nest [2]. Current blanking practice limits the potential to nest parts as cutting heads must be manufactured months in advance and production volumes may not match between different sectors. However, if a cutting medium rather than a shearing process were employed this restriction would be gone and flexible nested blanking (FNB) can be employed where nestings can be determined in a short time frame to fit the exact number of parts needed in each geometry with the most efficient nest available.

Until recently all cutting media were too slow to compete with press blanks at high production volumes. Water jets are restricted to small-volume, detailed thin-gauge applications while oxy-fuel and plasma cutting is only suitable for heavy gauge and plate components [4]. Lasers have also 
been restricted to small-volume applications due to cut quality and the long time required to manoeuvre the cutting head [21]. However, advances in fibre laser cutting have resulted in cutting speeds that now rival what can be achieved by presses. Worthington Special Processing, an American subcontractor, recently reported that a 25component, 500,000 car automotive job that would have taken $2100 \mathrm{~h}$ with a conventional press system would take $3400 \mathrm{~h}$ with a 2-head laser blanking system they recently employed while consuming the same amount of power and employing fewer staff.

It is likely that a FNB scheme will be substantially more materially efficient due to reduced coil trimming, part spacing and more optimal part nesting, though a question remains: Would the material cost savings of such a process justify the higher price tag per tonne processed with a more expensive technology? In this paper, we explore the conditions that determine whether switching to a more materially efficient process is economically as well as environmentally viable. Furthermore, using a dataset of European flat steel orders for the period 2011-2016, we determine the material and carbon savings that could be achieved by switching to a FNB scheme for a single vehicle model as well as across the whole automotive supply chain and the processing costs under which such a change is economically viable.

\section{Conditions for switching to a more efficient process}

In order to switch to a more materially efficient process, manufacturers must be assured that the new process will result in net financial savings-not just $\mathrm{CO}_{2}$ savings. In this section, we present a framework for assessing the costs and savings associated with such a process switch and determine the conditions under which such a switch would have been profitable.
Consider a process, $P$, as shown in Fig. 2a that annually transforms a mass of raw material, $m_{m}$, into a mass of goods, $m_{g}$, and scrap, $m_{s}$. The process yield is $\eta$ such that $m_{g}=\eta m_{m}$ and $m_{s}=(1-\eta) m_{m}$. It costs $C_{p}$ per tonne to run this process, and the material, goods and scrap each have a price per tonne, $C_{m}, C_{g}$ and $C_{s}$ respectively. The value added from this process every year, $V$, is therefore given by the value of the outputs minus the inputs and the cost of operation:

$V=C_{g} m_{g}+C_{s} m_{s}-\left(C_{m}+C_{p}\right) m_{m}$

Considering $\eta$, this can be written in terms of $m_{m}$ only:

$V=\left[\eta C_{g}+(1-\eta) C_{s}-\left(C_{m}+C_{p}\right)\right] m_{m}$

Consider now replacing process $P$ with a new process, $P^{\prime}$, that produces the same mass of goods from the raw material but has a different yield, $\eta^{\prime}$, and cost, $C_{p}^{\prime}$, as shown in Fig. 2b. These two yields can be related by the yield change, $\Delta$ :

$\eta^{\prime}=\eta+(1-\eta) \Delta, \quad-\left(\frac{\eta}{1-\eta}\right)<\Delta<1$

If we require the same output from both processes, $m_{g}^{\prime}=$ $m_{g}$, then the new input mass can be given by:

$m_{m}^{\prime}=\frac{\eta}{\eta^{\prime}} m_{m}$

and the new value added in terms of $m_{m}$ will be:

$V^{\prime}=\left[\eta C_{g}+\left(\frac{\eta}{\eta^{\prime}}-\eta\right) C_{s}-\frac{\eta}{\eta^{\prime}}\left(C_{m}+C_{p}^{\prime}\right)\right] m_{m}$

It will be worth switching to this new process if $V^{\prime}>V$, and therefore subtracting (2) from (5) and dividing by $m_{m}$ gives the criterion:

$C_{s}\left(\frac{\eta}{\eta^{\prime}}-1\right)+C_{m}\left(1-\frac{\eta}{\eta^{\prime}}\right)+C_{p}-\frac{\eta}{\eta^{\prime}} C_{p}^{\prime}>0$

As outputs were constrained to be equal in both processes, Eq. 6 does not depend on $C_{g}$, meaning only
Fig. 2 a Mass flows for a process $P$ with yield $\eta$ that transforms raw material into goods and scrap. b Mass flows for a new process $P^{\prime}$ with the same output but different yield $\eta^{\prime}$

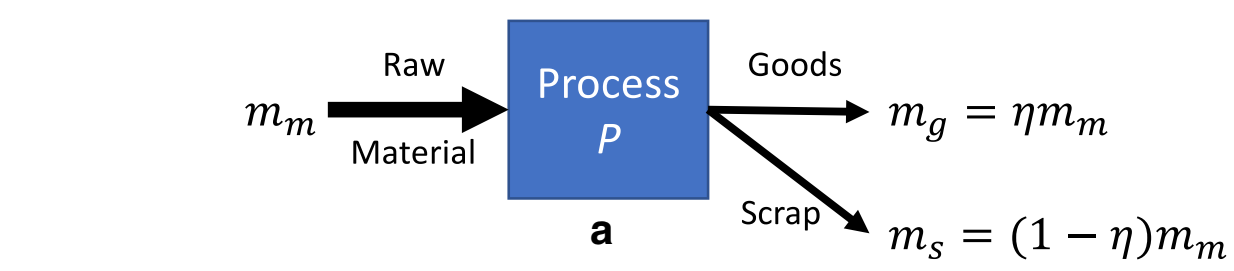

$$
m_{m}^{\prime}=\frac{\eta}{\eta^{\prime}} m_{m} \underset{\text { Material }}{\stackrel{\substack{\text { Raw } \\ P^{\prime}}}{\text { Process }}} \stackrel{\substack{\text { New } \\ \text { Scrap }}}{m^{\prime}{ }_{s}=\frac{\eta\left(1-\eta^{\prime}\right)}{\eta^{\prime}} m_{m}}
$$


material and scrap prices are relevant. Rearranging Eq. (6) gives the maximum viable process cost ratio $C_{p}^{\prime} / C_{p}$ :

$\frac{C_{p}^{\prime}}{C_{p}}<\frac{\eta^{\prime}}{\eta}+\frac{C_{m}-C_{s}}{C_{p}}\left(\frac{\eta^{\prime}}{\eta}-1\right)$

Equation 7 shows that this condition is a function of only two parameters: the yield ratio, $\eta^{\prime} / \eta$, and the difference between material and scrap prices divided by the original process cost, $\left(C_{m}-C_{s}\right) / C_{p}$, which we will call the price ratio. Increases in the yield ratio result in a higher allowable cost for the new process, which further increases linearly with the price ratio. This relationship has been plotted for five yield ratios in Fig. 3. Each line represents a break-even point, and thus the area under each shows the price and cost ratios where the switch would be more cost-effective. For example, assume $C_{m}=€ 700, C_{s}=€ 200$, and $C_{p}=€ 100$ giving a price ratio of 5 . If switching from a process with $\eta=50 \%$ to $\eta^{\prime}=52 \%$, giving a yield ratio of 1.04 , then the new process could cost up to $24 \%$ more and still result in a net savings.

The same analysis can be applied by considering carbon costs rather than financial prices. Table 2 shows the $\mathrm{CO}_{2}$ emissions embodied in various categories of steel and scrap, our new values of $C_{m}$ and $C_{s}$, along with the emissions associated with blanking and stamping, $C_{p}$. Note that $C_{s}$, the embodied carbon in scrap, is the embodied emissions of liquid steel, $1.47 \mathrm{t} \mathrm{CO}_{s} / \mathrm{t}$, minus the emissions produced per tonne of output in a $100 \%$ scrap electric arc furnace (EAF) process, $0.386 \mathrm{t} \mathrm{CO}_{s} / \mathrm{t}$, divided by the average EAF yield

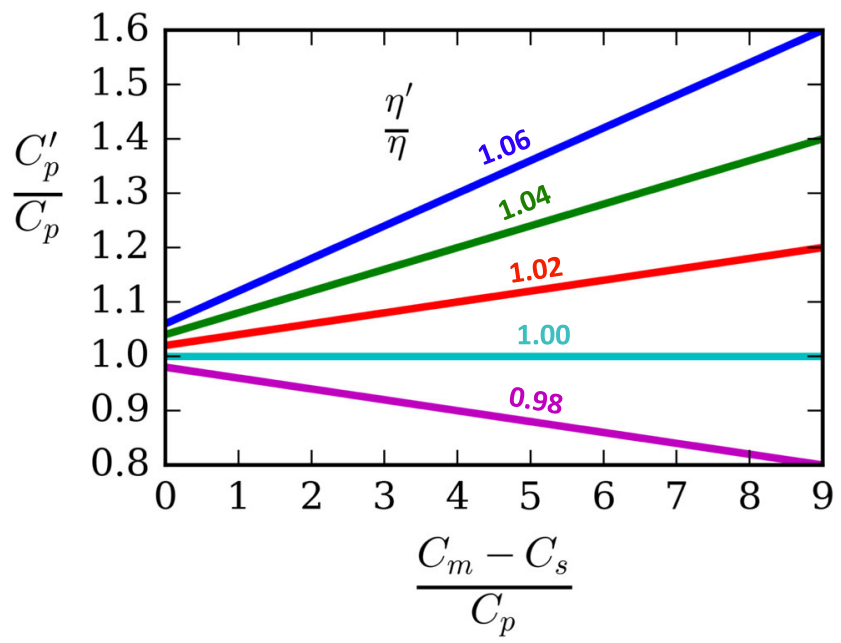

Fig. 3 Equation 7 plotted to show the maximum ratio of the new $\left(C_{p}^{\prime}\right)$ and original $\left(C_{p}\right)$ production cost vs. the difference between material $\left(C_{m}\right)$ and scrap $\left(C_{s}\right)$ prices divided by the original production $\operatorname{cost}\left(C_{p}\right)$ for yield ratios ranging from 0.98 to 1.06 . The area under each line shows the conditions where switching to the new process $P^{\prime}$ would result in a net savings
Table 2 Late 2017 prices for flat steel in Europe [19] and embodied $\mathrm{CO}_{2}$ emissions [24] as well as the emissions per tonne for three manufacturing processes according to Milford et al. [20]

\begin{tabular}{lll}
\hline Category & $€ / \mathrm{t}$ & $\mathrm{t} \mathrm{CO}_{2} / \mathrm{t}$ \\
\hline Hot rolled non-pickled & 546 & 1.94 \\
Hot rolled pickled & 580 & 2.13 \\
Cold rolled & 652 & 2.23 \\
Hot dip galvanised & 716 & 2.32 \\
Organic coated & 775 & 2.34 \\
Electrogalvanised & 733 & 2.28 \\
Other & 623 & 2.23 \\
Tin coated & 815 & 2.62 \\
Plate & 545 & 2.40 \\
Scrap & 201 & 0.99 \\
Coil processing & - & 0.02 \\
Blanking & - & 0.02 \\
Stamping & - & 0.07 \\
\hline
\end{tabular}

[6]. Considering hot dip galvanised steel and the emissions from blanking:

$\frac{C_{m}-C_{s}}{C_{p}}=\frac{2.32-0.99}{0.02}=66.5$

meaning a small improvement in yield ratio could justify switching to a substantially more carbon-intensive process while still resulting in carbon savings. For example, improving yield just $1 \%$ point from 80 to $81 \%$ would justify a new process that emits $84 \%$ more $\mathrm{CO}_{2}$ thanks to the reduction in liquid steel required to satisfy demand. Unless the new process is highly carbon-intensive, even small improvements in $\eta$ can result in substantial carbon savings.

This highlights a quandary that material efficiency research has struggled with: while the environmental incentives for switching to more efficient practices are clear, the economic incentives are far less substantial, especially when material prices are low relative to processing costs. Critically, it is economic incentives that drive manufacturing decisions. In the absence of a high carbon price to boost material prices relative to production costs, the yield improvement has to be substantial to justify switching to a new, likely more expensive process.

\section{Assessing savings from flexible nested blanking}

Figure $4 \mathrm{a}$ shows the conventional coil trimming and blanking scheme adopted by the automotive industry today. Areas shown in black are losses due to coil trimming while areas in dark blue are the losses that occur during blanking. 


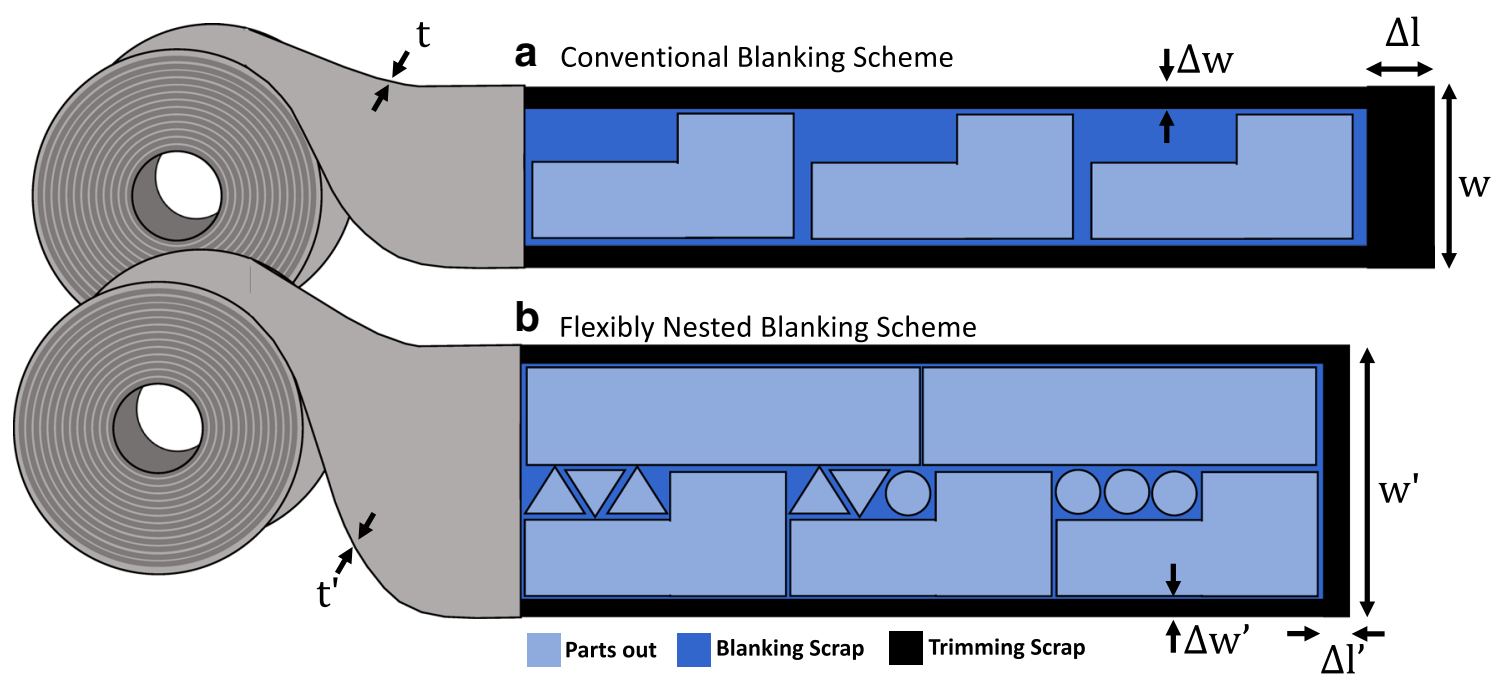

Fig. 4 a Conventional blanking practice showing coil trimming and blanking losses. b Flexible nested blanking, with reduced part spacing, more optimal nesting of parts and nesting variation across the width and length of the coil

Figure $4 \mathrm{~b}$ shows the proposed FNB scheme where coils are cast as wide as possible and the use of a cutting medium allows tightly packed nests of parts that are able to vary flexibly across the width and length of the coil.

To assess the potential savings that such a switch can yield, we explore a database of orders spanning the years 2011-2016 from a large European steelmaker. Each order in this database is a mass of steel coil associated with a customer name, location, mill of origin, time of delivery and various material characteristics. Using the time and material information, we will determine the savings that could be achieved in both coil processing from wide coil casting and blanking from combining similar orders on the same coil.

\subsection{Coil processing}

Before blanking, manufacturers ensure that the steel they are working with is perfectly regular by leveling and then trimming the edges and ends of the coil. European standards guarantee a tolerance of no more than $6 \mathrm{~mm}$ above the ordered width for hot-rolled and cold-rolled steel and $8 \mathrm{~mm}$ for coated steel [10-12]. Lengths are also guaranteed to be no more than $0.15-0.30 \%$ above the ordered value. If $\Delta w$ and $\Delta l$ are the amount trimmed from the width $w$ and length $l$ on each side of a coil, then the yield of coil processing is given by:

$\eta_{c p}=1-\left(\frac{2 \Delta w l+2 w \Delta l-4 \Delta w \Delta l}{w l}\right)$

Figure 5 shows a histogram of yields for coils processed during a typical month at a steel service centre, demonstrating the range achieved as a result of length and thickness variation as well as variation in process control. Width, $w$, and thickness, $t$, are important dimensions for blanking process design, but not length, $l$, which only depends on the number of parts produced. Rearranging (9) considering the coil mass, $m$, and density, $\rho$, such that $m=$ $\rho t w l$ gives:

$\eta_{c p}=1-\frac{2 \Delta w}{w}-\frac{2 \rho t \Delta l}{m}(w-2 \Delta w)$

Equation 10 shows that yield is a function of width, thickness and casting mass as well as the trim lengths $\Delta w$ and $\Delta l$. Yield increases for casting coils heavier and thinner due to the reduced loss at the coil ends as well as wider to reduce the effect of edge trimming.

To calculate the new coil processing yield of each order, we assume that all orders are cast $2.0 \mathrm{~m}$ wide and at 25 tonnes, the maximum width and weight most steel mills will produce for a single coil, and that $\Delta w=8 \mathrm{~mm}$ and

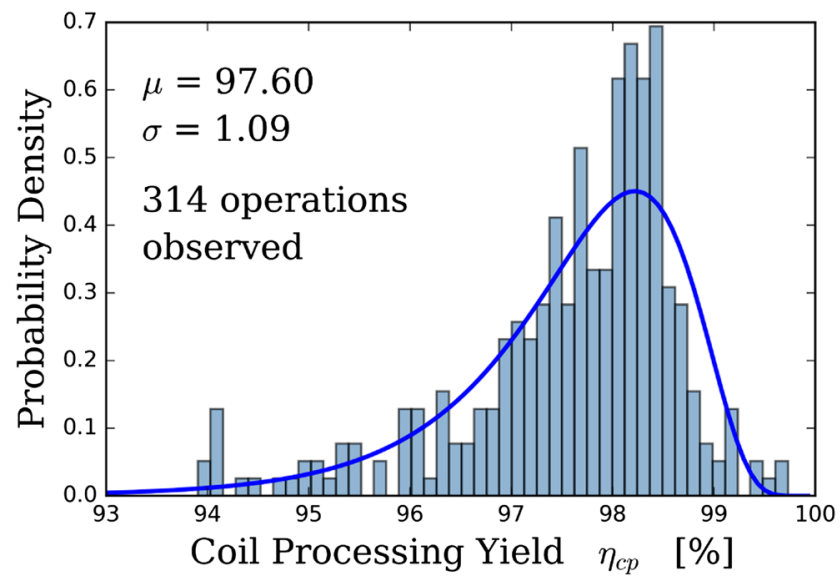

Fig. 5 Histogram of yields for 314 coils processed in a British steel service centre. The blue curve shows a lognormal distribution fit to the data 
$\Delta l=2.0 \mathrm{~m}$. This gives the new coil processing yield, $\eta_{c p}^{\prime}$ as a function of $t$ in millimetre:

$\eta_{c p}^{\prime}(t)=0.992-0.025 t$

\subsection{Blanking}

To determine the original blanking yield, consider Fig. 6a which shows a histogram of the blanking and stamping yield of all steel components in a light vehicle model produced in the EU in 2015. The vehicle has an average yield $\mu$ of just under $55 \%$ with a coefficient of variance $\sigma / \mu=0.297$. Figure $6 \mathrm{~b}$ further shows the same plot for average yields across 47 different models produced over the last ten years from Horton and Allwood's study [15]. We observed that the blanking scrap accounts for about $1 / 3$ of the average scrap yield, so using the industry average in Fig. $6 \mathrm{~b}$ and $\sigma / \mu=0.3$ we assign a blanking yield to each order using random samples from a normal distribution with $\mu=85 \%$ and $\sigma=4.5 \%$ :

Savings in the blanking process arise from reduced spacing of parts to just the kerf width of the cutting medium
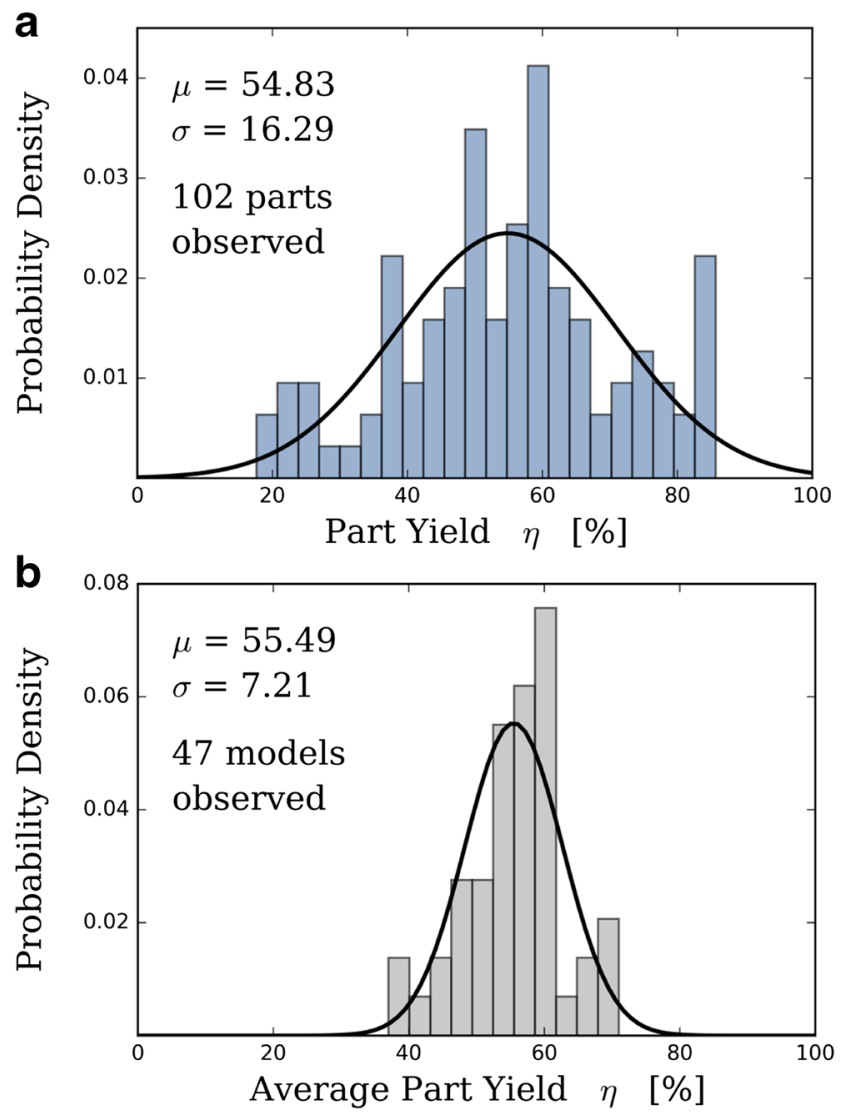

Fig. 6 Histograms of blanking and stamping yield for a each steel part in a light vehicle model produced in the EU and $\mathbf{b}$ the average of all parts across 47 models produced from 2007-2015. The black curves show normal distribution fits to the data and the more efficient nesting of parts. We assign a savings of $\Delta_{1}$ and $\Delta_{2}$ for part spacing and nesting respectively such that:

$\eta_{b}^{\prime}=\eta_{b}+\left(1-\eta_{b}\right) \Delta_{b}$, where $\Delta_{b}=\Delta_{1}+\Delta_{2}$

\subsubsection{Part spacing}

Based on an interview with a laser blanking process designer and their experience with customers switching from conventional press blanking to laser cut solutions, we estimate the yield improvement from part spacing is $\Delta_{1}=$ $10 \pm 2.5 \%$.

\subsubsection{Nesting}

Nesting efficiency is highly dependent on part geometry, information we do not have for this study. However, given a large enough cohort of parts with varying geometries, one or more combinations of those parts will likely lead to a better nesting efficiency than a single part on its own.

Consider a set of $N$-many parts that can be cut from the same coil of material. For small $N$, we assume that matches are unlikely, and the opposite for large values of $N$. As such we estimate that the probability of a match for any given part in that set is a bounded exponential function of $N$ :

$p($ match $)=1-e^{-k_{1}(N-1)}$

where $k_{1}=0.03$ is a shape parameter chosen such that the likelihood of a match is low when $N<5,50 \%$ when $N=25$, and nearly certain when $N>100$. In the no-match case, $\Delta_{2}=0$. If there is a match we assume an improvement is possible up to some limit. Based on the largest nestings observed in the literature, we set $N_{0}=25$ and estimate that $\Delta_{2}$ follows a logistic function of $N$ :

$\Delta_{2}(N$, match $)=\Delta_{\min }+\frac{\Delta_{\max }-\Delta_{\min }}{1+e^{-k_{2}\left(N-N_{0}\right)}}$

where shape parameters $k_{2}=0.05$ and $N_{0}=25$. These parameters were chosen such that $\Delta_{2}(N<25) \approx \Delta_{\text {min }}=$ $5 \%$ and $\Delta_{2}(N>100) \approx \Delta_{\max }=25 \%$, where $\Delta_{\min }$ and $\Delta_{\max }$ are values based on interview with a laser blanking process designer.

$N$ for each order was determined by considering that order's characteristics and the range it can tolerate. First, orders were partitioned according to qualitative characteristics assuming that grade and coating must match, as well as the financial quarter of delivery. For each partition the range of quantitative characteristics-thickness $(t)$, tensile strength $(U T S)$, yield strength $(Y S)$, elongation $(E)$, and coating weight $(C)$ - that each order can tolerate were then considered. Figure 8a demonstrates an example set of orders plotted according to their thickness and UTS, 
while Fig. $8 \mathrm{~b}$ shows the partitioned orders remaining for Zn-coated orders only.

Figure 8c shows the range of $t$ and $U T S$ that a particular order can withstand, with only three out of fifteen other orders being suitable substitutes. Tolerances for $Y S, U T S$ and $E$ were assumed to be $\pm 2 \%$ based upon the difference between the discrete values for each of these characteristics offered by steel mills. Coating weight was assumed to have to remain the same or vary up to $100 \%$ thicker, a condition based on interviews with three British steel service centres. Finally, thicknesses were determined using European standards EN10051, 10131 and 10143 that define limits for thickness variation as a function of thickness and yield strength, as shown in Fig. 7. A safety factor $S_{t}=0.5$ was used with all thickness tolerances to reflect a higher
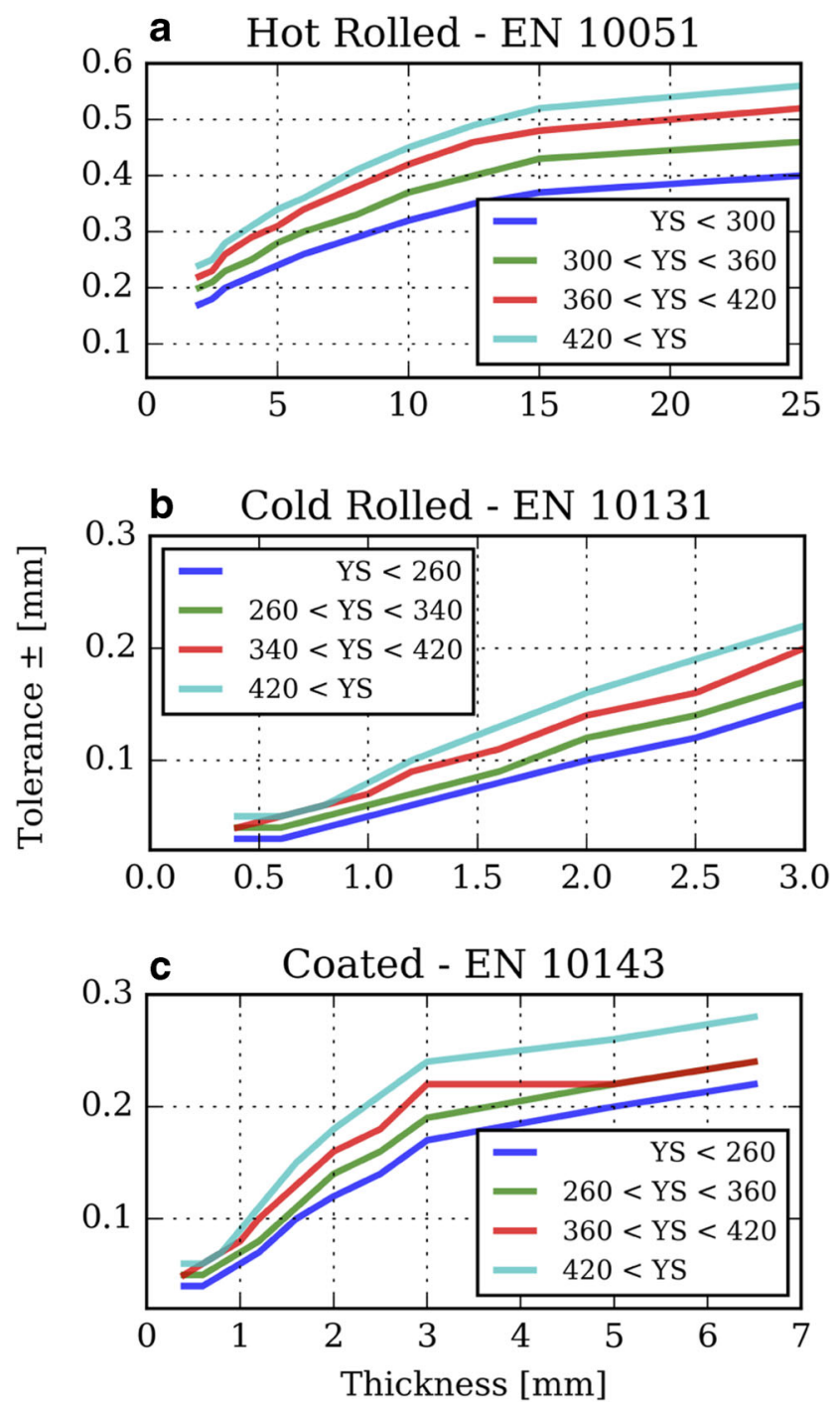

Fig. 7 Thickness tolerances for a hot-rolled, $\mathbf{b}$ cold-rolled and $\mathbf{c}$ coated steels as a function of thickness and yield strength according to European standards promise of tolerance that steelmakers aim to deliver above the European standard.

Figure $8 \mathrm{~d}$ shows each order with arrows connecting it to every other order that it can tolerate. Each partition can now be thought of as a directed graph, where each order is a node and the tolerance arrows act as edges that define the connectivity of that graph. The in-degree of each nodethe number of other orders that could tolerate that order-is displayed in white. By selecting nodes with the highest indegree first as group centroids, the largest possible groups were formed, with the size of the group defining $N$ for all orders within that group.

As Fig. 8e demonstrates, this first step may leave some orders isolated in $N=1$ groups when they can in fact tolerate other orders. To avoid this, each isolated order is visited in turn and the order it can tolerate with the highest in-degree is tested as a new centroid. This may displace an existing centroid and some of its allocated orders, necessitating a new allocation as shown in Fig. 8f. If this new allocation reduces the total number of groups, then this new allocation is kept in place of the previous one, reducing the total number of isolated orders. If the new number of groups is the same or higher, the previous allocation is kept in place.

Figure 9 shows a plot of the mass of orders in 2016 group size $N$ plotted on logarithmic axes. Nine percent of the orders remain isolated in $N=1$ groups and thus must be blanked from an individual coil. All other orders can tolerate at least one other order, where $58 \%$ of all orders have $N>25$. With $N$ established for each order, $\Delta_{2}$ can be determined for each order by Eq. 14 and then the new blanking yield for each order by Eq. 12 .

\section{Results}

The procedure described in Section 3 was performed for the years 2011-2016 using the model parameters shown in Table 3. As many parameters are assumed using the best available information, upper and lower bound values were employed to test the model's sensitivity to each parameter using a Monte Carlo approach where each parameter is randomly varied between the minimum and maximum value in 100 simulations, determining the range of new possible coil processing and blanking yields. All following values will be reported based on results using expected parameter values \pm the standard deviation observed from Monte Carlo simulation.

The new average coil processing yield across all years was $98.9 \pm 0.1 \%$, as would be expected from Eq. 11 given the average thickness of $1.41 \mathrm{~mm}$ for all orders. This represents a significant improvement on the original average of $98.0 \%$, resulting in $47 \pm 5 \%$ less scrap from 
Fig. 8 Demonstration of how orders are grouped according to material characteristics. a Orders plotted by thickness and ultimate tensile strength (UTS) and coloured by coating type. $\mathbf{b}$ Zn-coated partition only shown c Only three other orders have thickness and UTS tolerable to the order shown. $\mathbf{d}$ Edges are drawn from all orders to others they could tolerate. The number (in-degree) on each order indicates how many other orders can tolerate it. Two orders in this case remain isolated. e By selecting orders first with the highest in degree, the largest possible groups can be formed. $\mathbf{f}$ Each isolated node is visited in turn to see if it can be grouped with a currently allocated order to reduce the total number of groups. In this example, one order is left isolated $(N=1)$ to enable a $N=6$ group to form instead of $N=5$ and $N=2$ groups

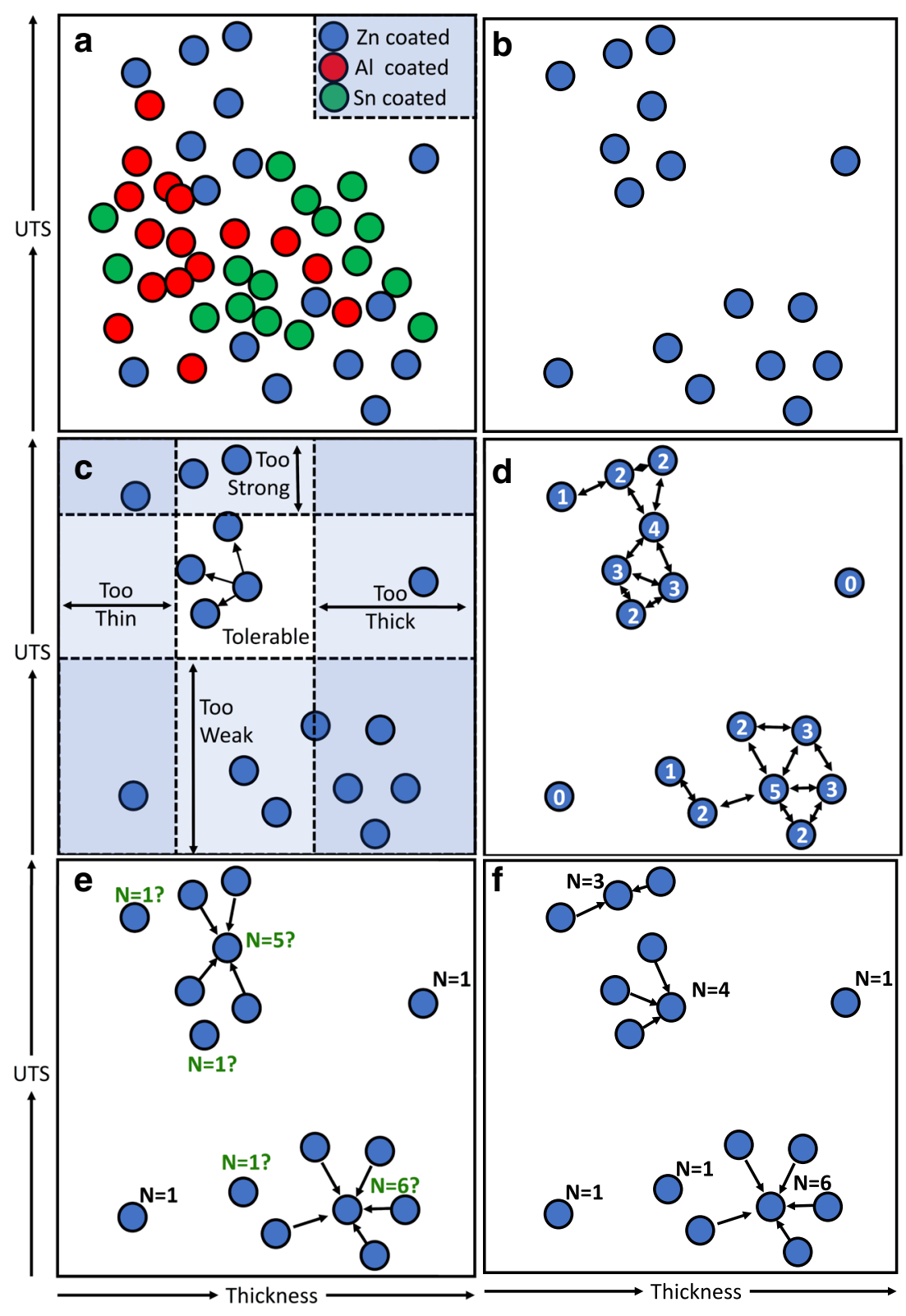

coil processing. The new blanking yield was $87.7 \pm 0.7 \%$. Considering the coil processing and blanking process yields together, we see that switching to a FNB system results in a net $3.4 \pm 0.8 \%$ point improvement, resulting in a yield ratio of $[1.041] \pm 0.009$.

Figure 10 shows the scrap, carbon and cost savings that could have been achieved for each year 2011-2016 if FNB had been adopted across the European automotive sector. This assumes the emissions and cost of FNB are the same per tonne as the original. To handle this assumption, we use the method developed in Section 2 to determine the break-even curves for switching to a FNB system as shown in Fig. 11 using cost data for the year 2016. Assuming the original blanking process costs $€ 100 / \mathrm{t}$ and emits $0.02 \mathrm{t}$ $\mathrm{CO}_{2} / \mathrm{t}$ input then the new process can cost up to $€ 25$ more per tonne and emit up to 3.9 times as much $\mathrm{CO}_{2}$ while still resulting in a net savings.

\section{Discussion}

Averaging across all six years in this study, $1.08 \pm 0.31 \mathrm{Mt}$ $\mathrm{CO}_{2}$ and $0.71 \pm 0.20 \mathrm{Mt}$ of steel worth $€ 0.43 \pm 0.12$ billion could be saved each year by adopting a FNB scheme with the same production costs as current practice. This is a $\mathrm{CO}_{2}$ savings equivalent to taking 650,000 cars off the road [13], or switching $265 \mathrm{MW}$ of coal-powered capacity to solar or wind [16].

The average European vehicle uses about $490 \mathrm{~kg}$ of steel in production, so for a 500,000 car production run, this 
Fig. 9 Mass of orders in each cohort of the number of orders they can tolerate. Note that orders in group size $N=1$ are the $9 \%$ of orders that cannot tolerate any other order's characteristics

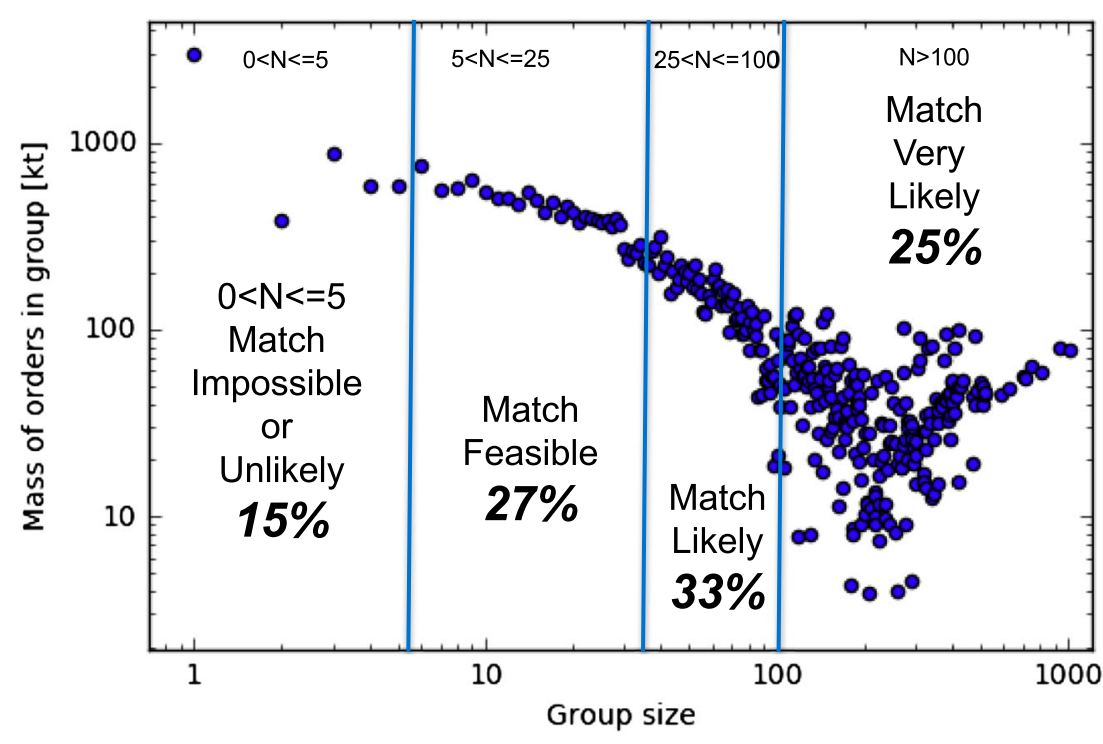

leads to a net savings of around $€ 5.8$ million. Though these savings are substantial, the new process is only able to cost up to $25 \%$ more than current practice. This means the new process must be able to closely match production speeds in blanking to minimise the costs of labour and overheads. Laser Coil Industries LLC estimate that the process they develop is about $60 \%$ as fast as press blanking for the same

Table 3 Model parameters employed in this study with minimum, expected and maximum values

\begin{tabular}{lllll}
\hline & & \multicolumn{2}{l}{ Value } \\
\cline { 3 - 5 } Parameter & Units & Min & Expected & Max \\
\hline$\rho$ & $\mathrm{kg} / \mathrm{m}^{3}$ & 7800 & 7800 & 7800 \\
$m$ & $\mathrm{~kg}$ & 20,000 & 25000 & 30,000 \\
$w$ & $\mathrm{~m}$ & 2 & 2 & 2 \\
$\Delta w$ & $\mathrm{~m}$ & 0.008 & 0 & 0.01 \\
$\Delta l$ & $\mathrm{~m}$ & 1 & 2.0 & 4 \\
$\eta b$ & $\%$ & 83.5 & 85 & 86.5 \\
$\sigma$ & $\%$ & 4.5 & 4.5 & 4.5 \\
$\Delta_{1}$ & $\%$ & 7.5 & 10 & 12.5 \\
$k_{1}$ & - & 0.015 & 0.03 & 0.045 \\
$k_{2}$ & - & 0.015 & 0.03 & 0.045 \\
$N_{0}$ & - & 50 & 100 & 150 \\
$\Delta_{1, \text { min }}$ & $\%$ & 2.5 & 5 & 7.5 \\
$\Delta_{1, \text { max }}$ & $\%$ & 12.5 & 25 & 37.5 \\
$Y S \pm$ & $\%$ & 1 & 2 & 3 \\
$U T S \pm$ & $\%$ & 1 & 2 & 3 \\
$E \pm$ & $\%$ & 1 & 2 & 3 \\
$C-$ & $\%$ & 0 & 0 & 0 \\
$C+$ & $\%$ & 50 & 100 & 150 \\
$S_{t}$ & & 0.25 & 0.5 & 1 \\
\hline
\end{tabular}

power requirement while employing only one worker and removing tooling costs.

However, such a new process is likely to be capitally intensive to install. Additional costs may arise if press cutting and forming are still required for some parts, and thus the expensive installation of press cutting and forming facilities may not be avoided. Although it seems theoretically feasible to implement laser cutting at

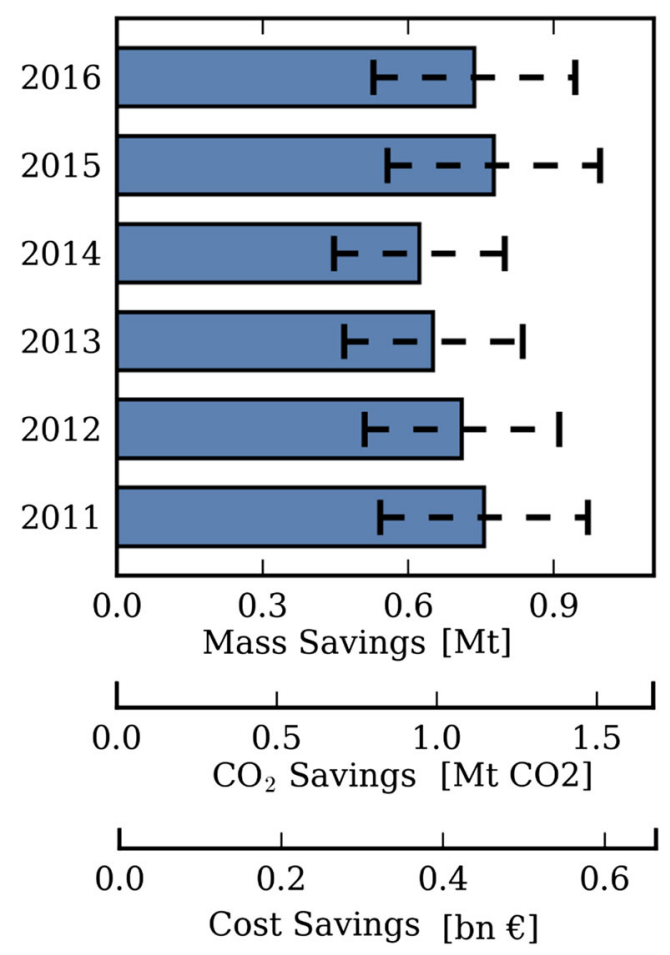

Fig. 10 Mass, $\mathrm{CO}_{2}$ and cost savings that could be realised from adoption of FNB in the European automotive steel market. Error bars account for one standard deviation away from the expected value 

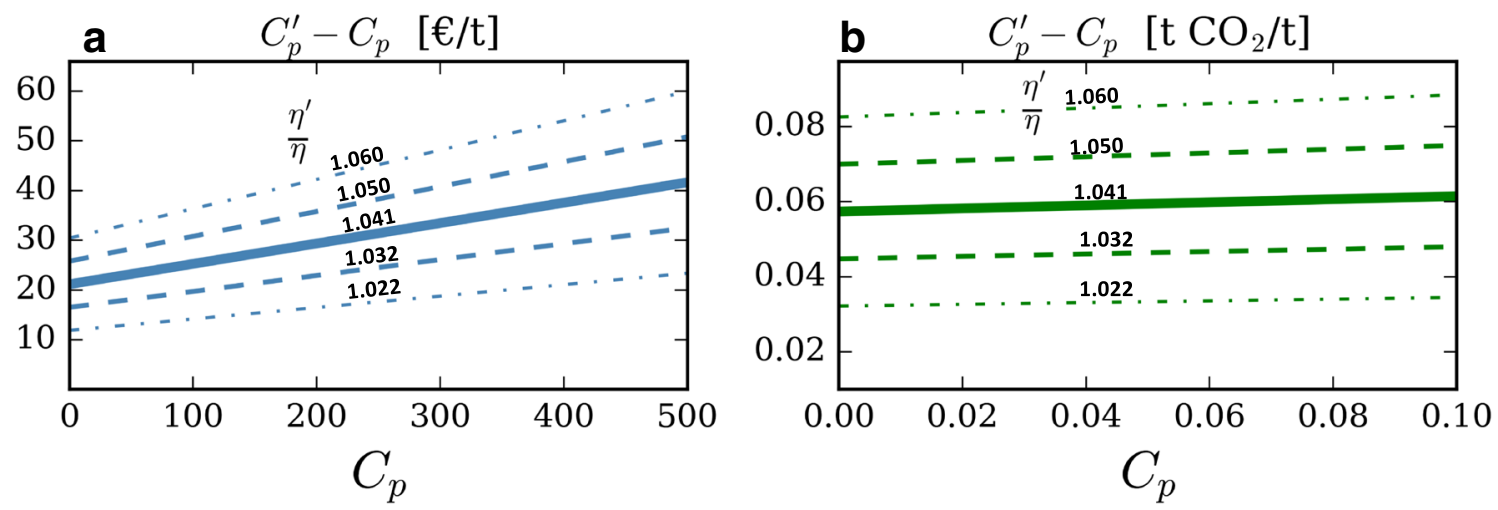

Fig. 11 Allowable increase in a production costs and $\mathbf{b}$ emissions against the original production cost and yield ratio. Solid lines show the expected yield ratio $(\mu=1.041)$ with the dashed lines either side showing the results for 1 and 2 standard deviations $(\sigma=0.0094)$ away from the expected yield ratio

reasonable costs and to adapt it to the complex logistics of the automotive industry, a detailed assessment of the practical viability of implementation by any given manufacturer would require specific information about individual production costs, supply chain configuration, and logistic specificities of each manufacturer. The logistic challenges and likely high capital cost described above, suggest that only large manufacturers may be able to afford installing the proposed system.

Several of the parameters used in our model are based on best estimates from the limited available data. To account for this, we have clearly laid out our assumptions and employed a Monte Carlo method. The standard deviation for the mass savings is $0.21 \mathrm{Mt}$, meaning we have an $84 \%$ confidence that at least $0.5 \mathrm{Mt}$ of steel could be saved. Should more concrete information for any parameter become available, the model employed in this work could be updated to give more precise results. Furthermore, the methods employed here could be extended to another region where detailed data about steel orders is available or could be adapted for similar industries such as aluminium.

\section{Future implementation}

The steel industry would enjoy clear benefits from implementing the scheme proposed in this paper. A typical rolling mill produces around one Mt of steel a year, meaning that at current prices around $€ 24$ million in savings could be realised at a single mill, justifying a large capital expenditure. As a further benefit, scrap from blanking could be kept within the steel mill and all information about the composition of that scrap retained, enabling direct recycling of high-quality grades of flat steel that is not possible with current industry practice [8]. For this reason, it is more likely that steelmakers would be interested in promoting the implementation of FNB, shifting their business model to selling blanks rather than coils of steel to automotive customers.

In such a scheme, manufacturers would communicate material properties as well as geometry and number of parts rather than length of coil to the steelmaker, who would then schedule the most efficient nest of parts given the geometries and volumes demanded of each material type. Manufacturers could even be offered a discounted price for shifting their material demands slightly to enable a more efficient nesting of parts. As another benefit, manufacturers would be able to change their part design much later in the design process, or get a new model to market faster than was previously possible.

Along with its benefits, the implementation of FNB would introduce substantial logistical issues for all stakeholders across the supply chain. Steel mills would have to manage another process in their supply chain and transform their goods handling and transport to handle pallets of blanks rather than coils of steel. Mills will also be competing with subcontractors and the blanking department of automotive firms who have historical experience in this area.

Moreover, automotive manufacturers require flexible just in time production, and the implementation of FNB would have to satisfy these requirements and thus be integrated in an already complex supply chain. Additionally, car manufacturers would have to communicate the part geometries they want, something not currently done in practice. Although FNB introduces new logistical complexities and the hiring of staff to manage, plan, run and maintain the blanking line, it is possible the cost savings from avoided steel production and the sale of a higher value product would justify the expenditure and provide European steel makers with a much needed competitive advantage. 


\section{Conclusions}

In this paper, we have determined for the first time the mass, $\mathrm{CO}_{2}$ and cost savings that could be achieved by adopting a flexibly nested blanking scheme in place of conventional press blanking. We have shown that the average yield can be improved from $85 \%$ to $87.7 \%$, as well as a $0.9 \%$ point improvement in losses from coil processing leading to a total savings of $0.71 \mathrm{Mt}$ of steel on the current consumption of $20.2 \mathrm{Mt}$ in the European automotive steel market. We have further highlighted the advantages of adopting such a scheme in steel mills. To account for the assumptions in our model we have employed a Monte Carlo method, showing a coefficient of variance of 0.283 in our mass savings figure. The methods laid out in this paper can easily be reproduced using different model parameters and probability distributions, or adapted for similar industries such as the aluminium sector.

Acknowledgements We would further like to thank the numerous experts in the steel and automotive industry who contributed interviews and data to enable our work.

Funding information This research received funding from the UK Engineering and Physical Sciences Research Council (EPSRC grant reference no. EP/N02351X/1) and ArcelorMittal.

Open Access This article is distributed under the terms of the Creative Commons Attribution 4.0 International License (http:// creativecommons.org/licenses/by/4.0/), which permits unrestricted use, distribution, and reproduction in any medium, provided you give appropriate credit to the original author(s) and the source, provide a link to the Creative Commons license, and indicate if changes were made.

\section{References}

1. Abdul Quader M, Ahmed S, Dawal SZ, Nukman Y (2016) Present needs, recent progress and future trends of energy-efficient UltraLow Carbon Dioxide (CO2) Steelmaking (ULCOS) program. Renew Sustain Energy Rev 55(2016):537-549. https://doi.org/10. 1016/j.rser.2015.10.101

2. Adamowicz M, Albano A (1976) Nesting two-dimensional shapes in rectangular modules. Comput Aided Des 8(1):27-33

3. Allwood JM, Cullen JM, Milford RL (2010) Options for achieving a $50 \%$ cut in industrial carbon emissions by 2050 . Environ Sci Technol 44(6):1888-94. https://doi.org/10.1021/es902909k

4. Beddoes J, Bibby MJ (1999) Principles of metal manufacturing processes. Butterworth-Heinemann

5. Bennell JA, Oliveira JF (2008) The geometry of nesting problems: a tutorial. Eur J Oper Res 184:397-415. https://doi.org/10.1016/j. ejor.2006.11.038
6. Broadbent C (2016) Steel's recyclability: demonstrating the benefits of recycling steel to achieve a circular economy. Int J Life Cycle Assess 21(11):1658-1665. https://doi.org/10.1007/s11367016-1081-1

7. Cook R, Grocock PG, Thomas PM, Edmonds DV, Hunt JD (1995) Development of the twin-roll casting process. J Mater Process Tech 55(2):76-84. https://doi.org/10.1016/0924-0136(95)01788-7

8. Daehn KE, Cabrera Serrenho A, Allwood JM (2017) How will copper contamination constrain future global steel recycling? Environ Sci Tech 51(11):6599-6606. https://doi.org/10.1021/acs. est.7b00997

9. Eurofer (2017) European steel in figures 2017 Edition. Tech rep

10. European Comission for Standardization (2006) BS EN 10131 Cold rolled uncoated and zinc or zinc-nickel electrolytically coated low carbon and high yield strength steel flat products for cold forming. Tolerances on dimensions and shape. Tech rep

11. European Comission for Standardization (2006) BS EN 10143 Continuously hot-dip coated steel sheet and strip. Tolerances on dimensions and shape. Tech rep

12. European Comission for Standardization (2010) BS EN 10051 Continuously hot-rolled strip and plate/sheet cut from wide strip of non-alloy and alloy steels. Tolerances on dimensions and shape. Tech rep

13. European Environment Agency (2017) CO2 emissions by car manufacturer. Tech. rep. https://www.eea.europa.eu/data-and-maps

14. Gao M, Huang H, Li X, Liu Z (2016) Carbon emission analysis and reduction for stamping process chain. Int $\mathrm{J}$ Adva Manuf Technol 91:667-678

15. Horton PM, Allwood JM (2017) Yield improvement opportunities for manufacturing automotive sheet metal components. J Mater Process Technol 249(May):78-88. https://doi.org/10.1016/j.jmat protec.2017.05.037

16. IEA (2015) Key coal trends - excerpt from: coal information. Tech rep

17. IPCC (2006) IPCC guidelines for national greenhouse gas inventories. Chapter 4 Metal Industry Emissions. Tech rep

18. Licari R, Lo Valvo E (2010) Optimal positioning of irregular shapes in stamping die strip. Int J Adv Manuf Technol 52:497505

19. MEPS International Ltd. (2018) MEPS EU carbon steel prices. http://www.meps.co.uk

20. Milford RL, Allwood JM, Cullen JM (2011) Assessing the potential of yield improvements, through process scrap reduction, for energy and $\mathrm{CO} 2$ abatement in the steel and aluminium sectors. Resour Conserv Recycl 55(12):1185-1195. https://doi.org/10. 1016/j.resconrec.2011.05.021

21. Powell J (1998) CO2 laser cutting, 2nd edn. Springer Limited, London

22. The World Steel Association (2015) Energy use in the steel industry. Tech rep

23. The World Steel Association (2017) Steel Statistical Yearbook 2017:1-128

24. The World Steel Association (2017) World steel in figures 2017. Tech rep

Publisher's note Springer Nature remains neutral with regard to jurisdictional claims in published maps and institutional affiliations. 